REGARDS

SUR LIECONOMIE ALLEMANDE

BULLETIN ECONOMIQUE DU CIRAC

\section{Regards sur l'économie allemande}

Bulletin économique du CIRAC

$65 \mid 2004$

Varia

\title{
Différences culturelles
}

UNTEREINER Gilles, Différences culturelles et management / SCHAUPP Gretchen, GRAFF Joachim, Business Etikette in Deutschland. So treten Sie professionell auf -Mind your Manners. Tips for Business Professionals Visiting Germany / WAGNER Doris, Kulturbier. Deutsche Kultur in der Bierplakatwerbung

\section{OpenEdition \\ Journals}

Édition électronique

URL : http://journals.openedition.org/rea/3957

DOI : 10.4000/rea.3957

ISBN : 978-2-8218-0826-3

ISSN : 1965-0787

Éditeur

CIRAC

Édition imprimée

Date de publication : 1 mars 2004

ISSN : 1156-8992

Référence électronique

"Différences culturelles », Regards sur l'économie allemande [En ligne], 65 | mars 2004, mis en ligne le 29 octobre 2009, consulté le 22 septembre 2020. URL : http://journals.openedition.org/rea/3957 ;

DOI : https://doi.org/10.4000/rea.3957

Ce document a été généré automatiquement le 22 septembre 2020.

(c) CIRAC 


\section{Différences culturelles}

UNTEREINER Gilles, Différences culturelles et management / SCHAUPP Gretchen, GRAFF Joachim, Business Etikette in Deutschland. So treten Sie professionell auf -Mind your Manners. Tips for Business Professionals Visiting Germany / WAGNER Doris, Kulturbier. Deutsche Kultur in der Bierplakatwerbung 


\section{RÉFÉRENCE}

UNTEREINER Gilles, Différences culturelles et management, Maxima Laurent du Mesnil Editeur, Paris, 2004, 310 p. SCHAUPP Gretchen, GRAFF Joachim, Business Etikette in Deutschland. So treten Sie professionell auf -Mind your Manners. Tips for Business Professionals Visiting Germany, Datakontext Fachverlag, Frechen, 2003, 214 p. WAGNER Doris, Kulturbier. Deutsche Kultur in der Bierplakatwerbung, Coll. Finnische Beiträge zur Gemanistik, vol. 10, Peter Lang, Francfort/Main, 2003, 150 p.

1 Fort de sa longue expérience à la tête de la CCI Française en Allemagne, G. UNTEREINER consacre là un solide ouvrage à cette « poison pill » que se révèle si souvent la différence culturelle. S'il livre analyses et réflexions pratiques aux décideurs français, on n'y trouvera pas de 'recettes'. Et pour cause: l'exercice du management interculturel " passe par une remise en cause de ce que l'on est». Un précieux conseil pour qui cherche à aborder un marché allemand très ouvert à l'international, comme le montre ce guide bilingue allemand-anglais qui passe en revue avec humour diverses situationstypes de la vie quotidienne et professionnelle. Explications et conseils permettent d'éviter les malentendus les plus classiques, mais aussi de présenter un dossier de candidature conforme aux règles en vigueur dans l'autre culture et, surtout, de prendre garde aux stéréotypes. L'un d'entre eux : «l'Allemand buveur de bière » a fasciné une germaniste allemande expatriée en Finlande (D. WAGNER ) au point qu'elle s'est penchée sur le lien entre cette boisson 'nationale' et l'évolution des tendances socioculturelles telles que les reflètent les affiches publicitaires. (IB) 